Case Report

\title{
Malignant mast cell tumor of the thymus in an Royal College of Surgeons (RCS) rat
}

\author{
Yui Terayama ${ }^{1}$, Tetsuro Matsuura ${ }^{1}$, and Kiyokazu Ozaki ${ }^{1 *}$ \\ ${ }^{1}$ Laboratory of Pathology, Faculty of Pharmaceutical Sciences, Setsunan University, 45-1 Nagaotoge-cho, Hirakata, Osaka 573-0101, \\ Japan
}

\begin{abstract}
A 152-week-old male Royal College of Surgeons (RCS) rat kept as a non-treated animal in a long-term animal study presented with a soft mass in the anterior mediastinum, which adhered to the pleura of the lung. Histopathologically, the mass mainly consisted of round to short spindle-shaped tumor cells that had infiltrated through the hyperplastic thymic tissue. The tumor cells were arranged in loose to dense sheets. Nuclei were moderate in size and round to spindle-shaped, with small nucleoli. Almost all tumor cells exhibited abundant eosinophilic cytoplasm, including eosinophilic granules of a range of sizes. The granules of tumor cells exhibited metachromasia with toluidine blue stain and were positive for c-kit and mast cell protease II. These findings indicate that the tumor described here represents a rare case of spontaneous malignant mast cell tumor with thymic epithelial hyperplasia. (DOI: 10.1293/ tox.2016-0044; J Toxicol Pathol 2017; 30: 63-67)
\end{abstract}

Key words: mast cell tumor, rat, thymus, eosinophilic granule, thymic epithelial hyperplasia

Mast cell tumors are extremely rare in rats: rat mast cell tumors have only been reported in two case reports and 12 cases in National Toxicology Program (NTP) pathology database entries ${ }^{1,2}$. Histopathologically, the mast cell tumors described in the two case reports originated in the thymus and in the eyelid, and they were reportedly characterized by sheet-like proliferation of the round cells and fine eosinophilic granules in the cytoplasm. However, infiltration of eosinophils and an increase in collagen fibers were not observed, unlike in cases of these tumors in dogs and cats $^{1-4}$. This report describes the histological characteristics of a spontaneous malignant mast cell tumor with thymic epithelial hyperplasia in a male Royal College of Surgeons (RCS) rat.

RCS/Kyo (RCS) rats were maintained at the National BioResource Project-Rat (NBRP-Rat) facility of Kyoto University (Japan). RCS rats are an inbred strain that is well known for its predisposition to inherited retinal degeneration; consequently, these rats are widely used for research on hereditary retinal dystrophy ${ }^{5-7}$. The progenitors of the RCS rats used in this study were obtained from the NBRPRat facility and maintained in our laboratory as an inbred

Received: 19 July 2016, Accepted: 12 September 2016

Published online in J-STAGE: 10 October 2016

*Corresponding author: K Ozaki

(e-mail: ozaki@pharm.setsunan.ac.jp)

(C)2017 The Japanese Society of Toxicologic Pathology

This is an open-access article distributed under the terms of the Creative Commons Attribution Non-Commercial No Derivatives (by-ncnd) License $<$ http://creativecommons.org/licenses/by-nc-nd/4.0/>. strain by full-sibling mating. A 152-week-old RCS male rat was reared in a barrier-sustained animal room maintained at a temperature of $24 \pm 2^{\circ} \mathrm{C}$ with a relative humidity of 60 $\pm 20 \%$, a $12 \mathrm{~h} \mathrm{light/dark} \mathrm{cycle,} \mathrm{and} \mathrm{ventilation} \mathrm{at} \mathrm{least} 12$ times $/ \mathrm{h}$. The rat was kept as a non-treated animal in a longterm study and fed a standard diet and chlorinated water ad libitum. Apart from coarse hair, no clinical signs were apparent until the scheduled sacrifice at 152 weeks of age. The rat was deeply anesthetized with a high dose of pentobarbital (Nembutal, Sumitomo Dainippon Pharma Co., Ltd., Osaka, Japan) and then euthanized by exsanguination. The study was approved by the Committee for Animal Experiments of Setsunan University. Grossly, a mass of $40 \times 30$ $\times 15 \mathrm{~mm}$ was observed in the anterior mediastinum. The mass was found to be adherent to the pleura on the right anterior lobe of the lung. Small masses (1-7 mm in diameter) that were adherent to the lung and the esophagus were identified around the main mass. The mass was soft, and the cut surface contained a milky white to yellow area with scattered petechia and gray-white area (Fig. 1). Specimens were fixed in $10 \%$ neutral phosphorylated formalin $(\mathrm{pH}$ 7.4), dehydrated in a graded series of ethanol, and embedded in paraffin. Sections $(4 \mu \mathrm{m})$ were subsequently stained with hematoxylin and eosin and toluidine blue stain. Immunohistochemical staining by a labeled polymer method was carried out using N-Histofine MAX PO rat (M or R) (Nichirei, Tokyo, Japan). The following primary antibodies were used: anti-human c-kit (1:200, rabbit polyclonal antibody, DAKO, Kyoto, Japan), anti-rat mast cell protease II (1:800, mouse monoclonal antibody, Moredun Scientific, Scotland, UK), anti-histamine (1:800, rabbit polyclonal an- 
tibody, Chemicon, Temecula, CA, USA), anti-cytokeratin AE1/AE3 (1:400, mouse monoclonal antibody, DAKO), antivimentin (1:400, mouse monoclonal antibody, DAKO), anti-cytokeratin 8 (pre-diluted, mouse monoclonal antibody, PROGEN, Heidelberg, Germany), and anti-cytokeratin 14 (1:1,200, mouse monoclonal antibody, BioGenex, Fremont, CA, USA).

Histopathologically, the mass was composed of an eosinophilic and a basophilic area, while the border region contained a mixture of both areas (Fig. 2A). The cell density of the eosinophilic area varied from sparse to dense, and round to short spindle-shaped tumor cells were arranged in loose to dense sheets. In the area with low cell density, tumor cells exhibited characteristics of cells of round cell tumors (Fig. $2 \mathrm{~B}$ and $2 \mathrm{C}$ ). In the area with high cell density, tumor cells were in contact with one another, and cell boundaries were indistinct. Nuclei were medium-sized and round to spindleshaped, with small nucleoli. Almost all tumor cells had abundant eosinophilic cytoplasm containing various-sized eosinophilic granules. The granules in the majority of tumor cells exhibited metachromasia with toluidine blue stain (Fig. 2D). Immunohistochemically, the tumor cells were positive for c-kit, strongly positive for rat mast cell protease II (Fig. 2E), and mostly negative for histamine; these three proteins are considered mast cell tumor markers. All tumor cells were negative for cytokeratin AE1/AE3 and positive for vimentin. Ultrastructurally, the various-sized granules contained nonstructural and homogeneous materials consistent with mast cell granules (Fig. $2 \mathrm{~F}$ and $2 \mathrm{G}$ ). The tumor had disseminated to the pleura of the lung and to the esophagus, as well as to the adventitia of the left ventricles and the aorta. No apparent metastasis was seen.

The basophilic area of the mass resembled normal thymic tissue in that it consisted of a large number of lymphocytes and thymic epithelial cells (Fig. 3A). The area with low epithelial cell density was formed within the high-epithelial cell density area. The epithelial cords were distributed throughout the high-epithelial cell density area, while cell nests and solid growth were not seen in the basophilic area of the mass. The hyperplastic epithelial cells had moderate to abundant eosinophilic cytoplasm with round to ovoid nuclei. Lymphocytes in the area with a high epithelial cell density were mostly small cells with coarse chromatin and were interspersed with a small number of large lymphocytes. However, lymphocytes in the area with a low epithelial cell density were mostly uniform medium-sized cells with fine stippled chromatin. Immunohistochemically, the thymic epithelial cells in the area with a high epithelial cell density exhibited positive staining for cytokeratin 8 (Fig. $3 \mathrm{~B}$ ), which is expressed in thymic cortical epithelial cells. The thymic epithelial cells in the area with a low epithelial cell density were positive for cytokeratin 14 (Fig. 3C), which is expressed in medullary epithelial cells.

The present tumor, which was located in the anterior mediastinum, had invaded the adjacent thymus tissues and disseminated to the thoracic cavity. The tumor was characterized by the dense proliferation of round to spindle-shaped

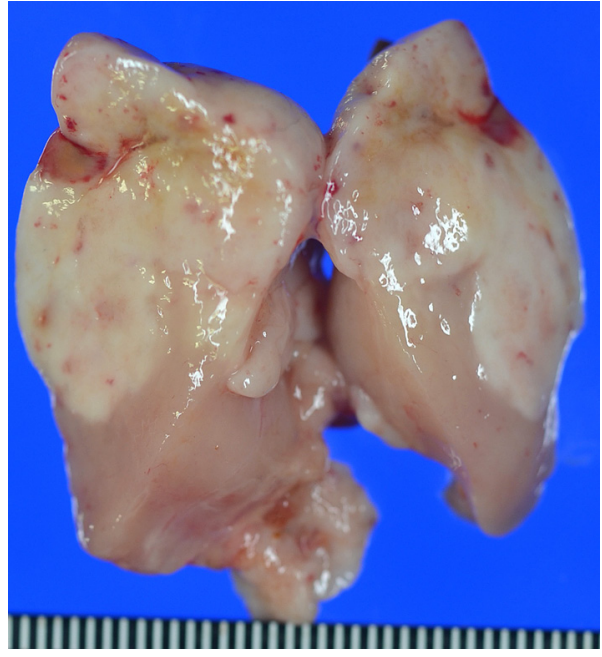

Fig. 1. The mass in the anterior mediastinum is soft, and the cut surface is milky white to yellow and gray-white in color.

cells and resembled a round cell tumor. The tumor cells exhibited metachromasia with toluidine blue stain as well as strong immunopositivity for mast cell markers. Based on these characteristics, the mass was diagnosed as a malignant mast cell tumor.

Mast cell tumors are common skin neoplasms in dogs and cats $^{3,4}$, where they are generally composed of round cells with eosinophilic and basophilic granules yielding metachromasia. With regard to rodents, chemical- and radiation-induced mast cell tumors, as well as spontaneous mast cell tumors, have been reported in mice ${ }^{8-12}$; however, to our knowledge, mast cell tumors are very rare in rats: only two case reports and 12 NTP pathology database entries exist for rat mast cell tumors ${ }^{1,2}$. The mast cell tumors in the two previous case reports originated in the thymus and in the eyelid and were characterized by sheet-like proliferation of the round cells as well as by the presence of fine eosinophilic granules in the cytoplasm. In the case reported here, highly similar morphological features were observed, suggesting that eosinophilic granules may be characteristic of mast cell tumors in rats. Although the tumor in the present case displayed a variety of cell and granule morphologies and dissemination, the degree of malignancy of the present tumor may have been greater than those of the previously reported cases.

Differential diagnoses for the present tumor included thymoma, granular cell tumor, and globule leukocyte tumor. Thymoma, an epithelial tumor, is easily distinguishable from a round cell tumor; however, the sheet-like proliferation observed in the present case resembled that in tumors of epithelial origin, thus making the rat tumor difficult to differentiate from thymoma. Immunohistochemical negative staining for cytokeratin AE1/AE3 provided the most definitive evidence required to distinguish the rat tumor from thymoma. Granular cell tumors and globule leukocyte tumors are characterized as round cell tumors 

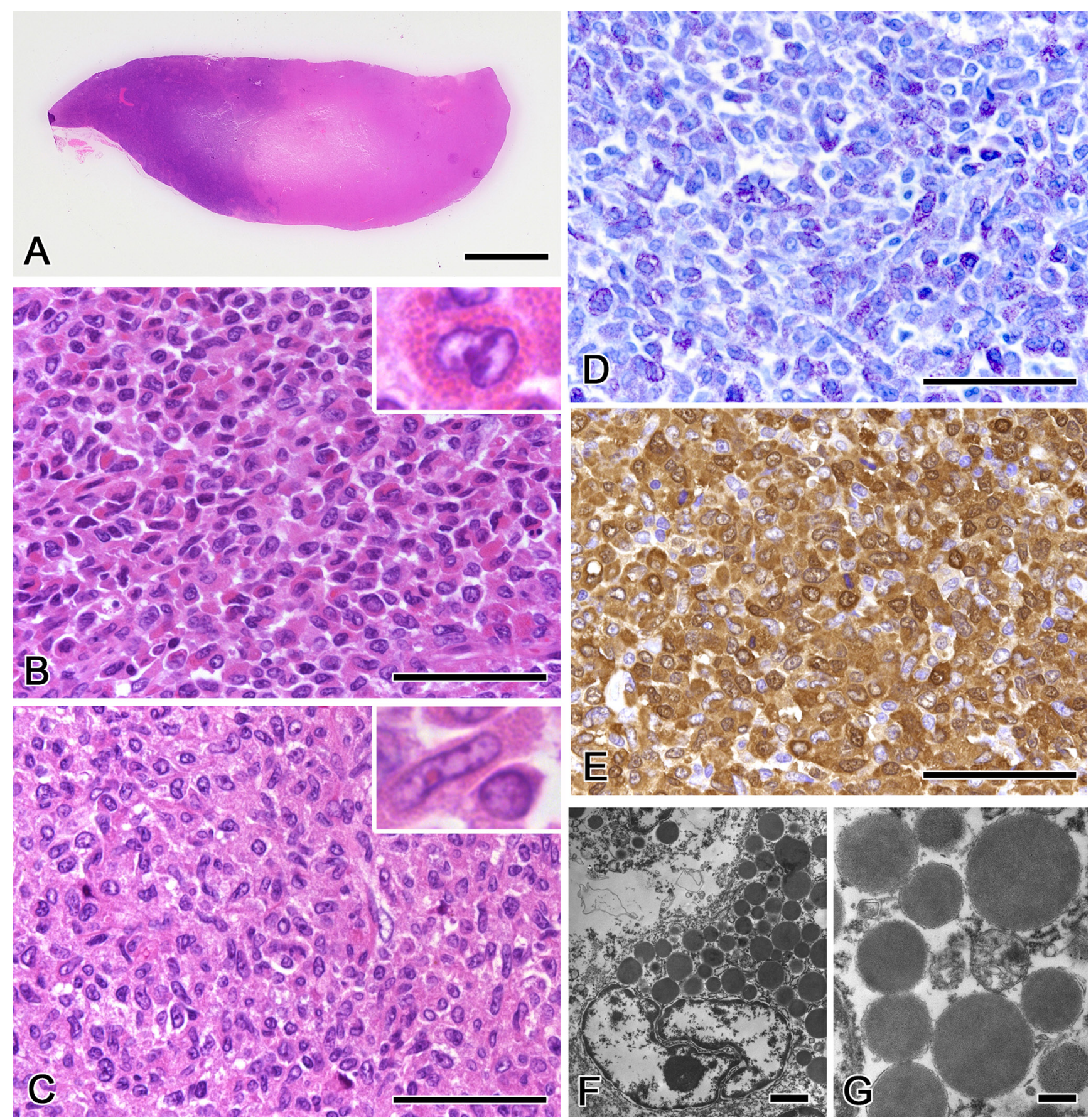

Fig. 2. (A) The mass is composed of an eosinophilic area with a mast cell tumor and a basophilic area with hyperplastic epithelial cells and numerous lymphocytes (HE stain; scale bar: $5 \mathrm{~mm}$ ). (B) Round tumor cells are arranged in dense sheets and possess small- to large-sized eosinophilic granules (HE stain; scale bar: $50 \mu \mathrm{m}$ ). Inset: enlarged image of cytoplasmic granules. (C) Round to short-spindled tumor cells include fine small-sized granules (HE stain; scale bar: $50 \mu \mathrm{m}$ ). Inset: enlarged image of cytoplasmic granules. (D) Cytoplasmic granules show metachromasia (toluidine blue stain; scale bar: $50 \mu \mathrm{m}$ ). (E) Immunoreactivity for rat mast cell proteinase II is detected; almost all tumor cells are strongly positive (scale bar: $50 \mu \mathrm{m}$ ). (F and G) The various-sized granules contain nonstructural and homogeneous materials consistent with mast cell granules (scale bar: $1 \mu \mathrm{m}$ for F; $200 \mathrm{~nm}$ for $\mathrm{G}$ ).

with eosinophilic granules, similar to those observed in the current case. Accordingly, metachromasia, using toluidine blue, was required to confirm the diagnosis ${ }^{1,2,13,14}$.

The thymic region of the tumor described here was composed of two areas with different densities, as well as different epithelial cell and lymphocyte morphologies, suggesting that cortical and medullary thymic components may have been maintained in the tumor. In humans, cortical and medullary thymic epithelial cells yield different expression patterns of cytokeratin: medullary thymic epithelial cells 

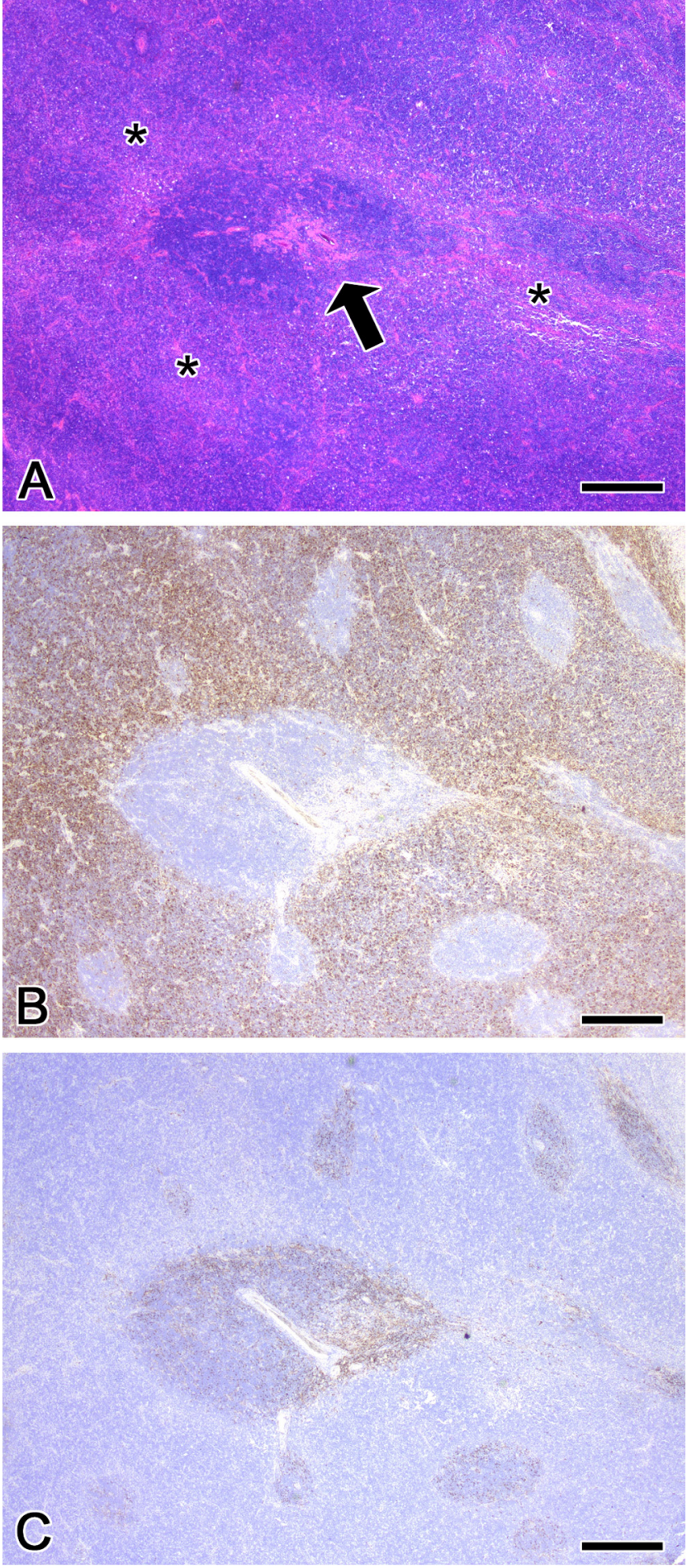

Fig. 3. (A) The basophilic area of the mass resembles normal thymic tissues. The area with a high epithelial cell-density $(*)$ is a combination of eosinophilic epithelial cells and basophilic lymphocytes. The area with a low epithelial cell density (arrow) consists mainly of basophilic lymphocytes (HE stain). (B) Cytokeratin 8 is expressed in the area with a high epithelial cell density, while (C) cytokeratin 14 is expressed in the area with a low epithelial cell density. Scale bar: $500 \mu \mathrm{m}$. express cytokeratin 5 and cytokeratin 14, whereas cortical thymic epithelial cells express cytokeratin 8 and cytokeratin $18^{15,16}$. Accordingly, immunohistochemical staining of cytokeratins definitively distinguishes between the cortex and the medulla. In this study, the expression patterns of cytokeratins 8 and 14 were analyzed in thymic epithelial cells of a normal RCS rat and shown to be similar to those observed in humans. Cytokeratins 8 and 14 were thus considered suitable markers for distinguishing between the cortex and medulla in RCS rats. In the RCS rat described here, the distribution of cytokeratins 8 and 14 corresponded to the areas with high and low epithelial cell densities, respectively. It was therefore clear that the thymic area described here possessed both cortical and medullary components but that the epithelial cell density differed from that of the normal thymus. However, growth of solid tubules and epithelial cords, which represent a characteristic feature of benign thymoma, was not observed in our case. The area exhibiting high epithelial cell density thus represented the cortical component of the tumor with thymic epithelial hyperplasia; accordingly, this region was diagnosed as thymic epithelial hyperplasia. In our laboratory, we previously detected only one benign thymoma in about $20 \mathrm{RCS}$ rats of over 120 weeks of age; however, almost all thymus showed severe involution. Therefore, this strain may not be prone to the development of thymic epithelial hyperplasia and thymoma.

Disclosure of Potential Conflicts of Interest: The authors declare that they have no competing interests.

\section{References}

1. Yamagishi Y, Katsuta O, and Tsuchitani M. Mastocytoma in a Fischer 344 rat. J Vet Med Sci. 54: 783-785. 1992. [Medline] [CrossRef]

2. Baselmans AH, Kuijpers MH, and van Dijk JE. Brief communication, Histopathology of a spontaneously developing mast cell sarcoma in a Wistar rat. Toxicol Pathol. 24: 365369. 1996. [Medline] [CrossRef]

3. Misdorp W. Mast cells and canine mast cell tumours. A review. Vet Q. 26: 156-169. 2004. [Medline] [CrossRef]

4. Hosseini E, Pedram B, Bahrami AM, Moghaddam MH, Javanbakht J, Ghomi FE, Moghaddam NJ, Koohestani M, and Shafiee R. Cutaneous mast cell tumor (Mastocytoma): cyto- histopathological and haematological investigations. Diagn Pathol. 9: 9. 2014. [Medline] [CrossRef]

5. LaVail MM, Sidman RL, and Gerhardt CO. Congenic strains of RCS rats with inherited retinal dystrophy. J Hered. 66: 242-244. 1975. [Medline]

6. Strauss O, Stumpff F, Mergler S, Wienrich M, and Wiederholt M. The Royal College of Surgeons rat: an animal model for inherited retinal degeneration with a still unknown genetic defect. Acta Anat (Basel). 162: 101-111. 1998. [Medline] [CrossRef]

7. Tsuji N, Ozaki K, Narama I, and Matsuura T. Inferior ectopic pupil and typical ocular coloboma in RCS rats. Comp Med. 61: 378-384. 2011. [Medline] 
8. Haseman JK, Hailey JR, and Morris RW. Spontaneous neoplasm incidences in Fischer 344 rats and B6C3F1 mice in two-year carcinogenicity studies: a National Toxicology Program update. Toxicol Pathol. 26: 428-441. 1998. [Medline] [CrossRef]

9. Dunn TB, and Potter M. A transplantable mast-cell neoplasm in the mouse. J Natl Cancer Inst. 18: 587-601. 1957. [Medline]

10. Miyakawa Y, Sato SI, Kakimoto K, Takahashi M, and Hayashi Y. Induction of cutaneous mast cell tumors by Nmethyl-N'-nitro-N-nitrosoguanidine followed by TPA in female mice of 4 out of 5 strains tested. Cancer Lett. 49: 19-24. 1990. [Medline] [CrossRef]

11. Frith $\mathrm{CH}$, Sprowls RW, and Breeden CR. Mast cell neoplasia in mice. Lab Anim Sci. 26: 478-481. 1976. [Medline]

12. Sass B. The occurrence of a bilateral mandibular mast cell neoplasm in a mouse with lymphocytic leukemia. Lab
Anim Sci. 29: 492-494. 1979. [Medline]

13. Miyajima R, Hosoi M, Yamamoto S, Mikami S, Yamakawa $\mathrm{S}$, Iwata $\mathrm{H}$, and Enomoto M. Eosinophilic granulated cells comprising a tumor in a Fischer rat. Toxicol Pathol. 27: 233-236. 1999. [Medline] [CrossRef]

14. Nagatani M, Nakamura A, Yamaguchi Y, Aikawa T, and Tamura K. Spontaneous eosinophilic granulated round cell tumors in rats. Vet Pathol. 38: 317-324. 2001. [Medline] [CrossRef]

15. Sun L, Li H, Luo H, and Zhao Y. Thymic epithelial cell development and its dysfunction in human diseases. BioMed Res Int. 2014: 206929. 2014. [Medline] [CrossRef]

16. Lee EN, Park JK, Lee JR, Oh SO, Baek SY, Kim BS, and Yoon S. Characterization of the expression of cytokeratins 5,8 , and 14 in mouse thymic epithelial cells during thymus regeneration following acute thymic involution. Anat Cell Biol. 44: 14-24. 2011. [Medline] [CrossRef] 